\title{
miscellany
}

\section{Gender Recognition Act 2004}

\section{Information for medical practitioners and chartered psychologists}

Transsexual people have long lived in a state of limbo between the gender in which they live and the gender in which they were born, because that was how the law defined them. They are affected by the condition gender dysphoria ( $a$ medical condition recognised by the Chief Medical Officer) or gender identity disorder. The Gender Recognition Act 2004 remedies this situation and allows transsexual people who have taken decisive steps to live fully and permanently in their acquired gender to apply for legal recognition of that gender.

The Act establishes Gender Recognition Panels with the power to assess applications from transsexual people seeking legal recognition in their acquired gender. The panels will begin sitting in April 2005. Applicants will have to provide evidence supporting their applications in accordance with prescribed legal and medical criteria. They will need to satisfy the panel that they:

1. have or have had gender dysphoria;

2. have lived in the acquired gender for two years prior to the application;

3. intend to live permanently in the acquired gender.

The evidence that applicants are required to provide must include, among other things:

- two reports from registered medical practitioners, one of whom must be practising in the field of gender dysphoria

- alternatively, a report from a registered medical practitioner and a report from a chartered psychologist practising in the field of gender dysphoria

- a sworn statement from the transsexual person declaring that he or she has lived in the acquired gender for the past two years and intends to do so until death.

The medical reports must be provided by a registered medical practitioner or a chartered psychologist, contain details of a diagnosis of gender dysphoria and contain details of the treatment the applicant has undergone, is undergoing or has planned for the purpose of modifying sexual characteristics.

Medical proformas will be provided for applicants' medical practitioners or chartered psychologists to complete (if they so wish). Alternatively, medical practitioners or chartered psychologists may prefer to give their patient copies of their notes and/or letters about their case. It will be at the medical practitioners or chartered psychologists' discretion as to whether they choose to charge their patient for the medical reports.

Questions regarding the Gender Recognition Act 2004 can be directed to the Department of Constitutional Affairs Gender Recognition Project who are responsible for the Act and the Government policy on transsexual people. They can be contacted on 0207210 8205, GRA@dca. gsi.gov.uk, or via www.dca.gov.uk/ constitution/transsex.

\section{forthcoming events}

\footnotetext{
Applications are now invited for

Semester Two of the MRCPsych

Course run by University College London.

Part I takes place on Monday afternoons

commencing 7 March 2005 and Part II

takes place on Tuesday afternoons

commencing 1 March 2005. The course

has been updated in keeping with the

Royal College of Psychiatrists syllabus and

includes mock exams, theme-specific

revision sessions and patient perspectives.

For further information and an application

form please contact Lydia M. Clinton, the
}

\section{Course Administrator (tel: 0207679}

9475; e-mail: mrcpsych@ucl.ac.uk).

The University of Surrey, Guildford 64th

Residential Revision Course for the

MRCPsych Examinations will be held on

(Part I) 30 March 2005-6 April 2005 and

(Part II) 6-14 April 2005. For further

details please contact Mrs S. Caines,

Belmont Postgraduate Centre, Chiltern

Wing, Sutton Hospital, Sutton, Surrey,
SM2 5NF (tel: 0208296 4177; e-mail:

shirley.caines@swlstg-tr.nhs.uk).

\section{The 14th European Congress of}

Psychiatry will take place in Nice, France on 4-8 March 2006. For further information please contact: 14th European Congress of Psychiatry, Kenes International Global Congress Organisers and Association Management Services, 17 Rue du

Cendrier, PO Box 1726 CH-1211 Geneva 1, Switzerland (tel: +41 22908 0488; fax: +41 22732 2850; e-mail: aep2006@ kenes.com). 